\title{
Perception of School Moral Atmosphere and Elementary Students' Moral Development
}

\author{
Parvin Kadivar, ${ }^{1}$ Naeimeh Kohoulat,, ${ }^{1,}$ Mohammad Hossein Abdolahi, ${ }^{1}$ and Fariba Khoshbakht ${ }^{2}$ \\ ${ }^{1}$ Faculty of psychology and education, Kharazmi University, Tehran, IR Iran \\ ${ }^{2}$ Faculty of psychology and education, Shiraz University, Shiraz, IR Iran \\ "Corresponding author: Naeimeh Kohoulat, Educational Psychology Department, Kharazmi University, Tehran, IR Iran. Tel: +98-9177005527, E-mail: Nkkohoulat@gmail.com
}

Received 2016 January 03; Revised 2016 January 18; Accepted 2016 January 20.

\begin{abstract}
Background: In the recent years, understanding school environment's contributions to students' development has been of increasing concern. One of the variables that could be affected by the school moral atmosphere is moral development.

Objectives: The purpose of this study was to assess the effect of students' perception of school moral atmosphere on their moral development.

Patients and Methods: The statistical population consisted of the students of Shiraz elementary schools. Multi-stage cluster random sampling was used to select 412 participants (grade four to six students) from different schools. They completed self-report questionnaires tapping school moral atmosphere questionnaire (SMAQ) and moral judgment test (MJT) in the classroom during a school lesson. All descriptive statistics, regression, and confirmatory factor analyses were performed with the SPSS 19 software.

Results: Simultaneous multiple regression of school moral atmosphere on students' moral development showed that subscales of the school moral atmosphere predict students' moral development. These findings are discussed fully in the results section.

Conclusions: The findings showed that perception of school moral atmosphere is a significant factor in predicting students' moral development. More specifically, these findings highlight the importance of improving the moral atmosphere of schools for the benefit of all members of the school community.
\end{abstract}

Keywords: Moral Atmosphere, Moral Development, Elementary Student

\section{Background}

Morality is central to human life (1). Authors and researchers have proposed different definitions of morality. Windmiller, Lambert and Turiel (1980) suggested that to behave morally is to have internalized the controls on behavior that inhibit harmful acts and facilitate beneficial acts (acts that promote the well-being of others) (P. 138), (cited in Wachob (2)). According to Rest (1986), the function of morality is optimizing mutual benefit of people living together in groups (P. 1). Rest borrowed from Rawls's (1971) statement and suggested, it is morality's special province to provide guidelines for determining how the benefits and burdens of cooperative living are to be distributed (cited in Sabin (3)). Historically, philosophers have debated about constituting moral decision, evaluating morality, and developing this among people (3-5). According to the definition common in psychology, moral development is a process of reaching the feeling of justice in relation to others, the correctness, or incorrectness of this matter, and the way the person behaves in each of these matters. As psychologists such as Piaget and Kohlberg say, in this definition, moral development means change in how children reason regarding moral issues, their attitude toward law-breaking, and their behavior when facing moral issues (6-9).

Until recently, researches on moral development were primarily concerned with moral competence or moral judgment; this is the highest level of moral judgment that a person achieves when we asked them to reason about abstract hypothetical moral dilemmas (10). In another word, moral competence or moral judgment refers to affective orientation for performing altruistic behaviors and also the ability to judge moral dilemmas and issues logically (11, 12).

These studies grew out of Kohlberg's developmental theory of moral judgment (10). His theory has gained a lot of attention in educational psychology discussions (6). Kohlberg $(1958,1976$, and 1986) says moral-reasoning shapes during various stages of life (from childhood to adolescence) and moral development results from this (cited in Westman (13)). He expressed that moral reasoning and judgment occurs in a sequence of three levels and each level consists of two stages, for a total of six. Kohlberg 
believed that each child starts out at the pre-conventional level, reasoning strictly in terms of ego-centered considerations. In stage one; the child initially focuses on avoidance of punishment. Then and in stage two, he or she focuses on satisfaction of self-interests. Next and in stage three, he or she follows the conventional level and a shift to group-centered considerations. At this stage, the focus is on pleasing one's family and other groups to which one belongs. At stage four, the focus is on maintaining social order. The third post-conventional level goes beyond both the self and one's society. Kohlberg did not believe that everyone reaches this level. In stage five of this level, the person emphasizes on democratic procedures and social utility, and in stage six, they formulate universal principles pertaining to justice and individual rights (14).

Some of the approaches have stressed the on contextual specificity of moral judgment. Actually, they recognized that moral judgment in real life is not only social in reference (i.e., it refers to human interactions), but also mostly arises in social situations and is shared with members of the group to which one belongs. As a result, the traditional approach has been supplemented with a more social approach. In this approach, subjects are not only asked to reason about real-life dilemmas from their own perspective, that is called practical moral judgment, but also to take the perspective of the majority of the context or group in which they participate. The perception of individuals regarding these shared norms and values regulating social interactions in moral situations make up the moral culture or moral atmosphere of an institution or a group (10). Obviously, the school is a significant social context from childhood to adolescence. The effect of the perceived school moral atmosphere on real-life moral behavior and moral judgment may be particularly strong during in these two age periods (15).

School moral atmosphere has originated from a popular approach that has been described as the school as community or the school as involving a sense of community. A community is a social organization whose members know, care about and support one another, have common goals and a sense of shared purpose, and to which they actively contribute and feel personally committed. Solomon et al. discussed different versions of the community concept, one of these being provided by Kohlberg's 'just community' approach, which inspired the current research. The just community approach is well known for its potential to transform the moral atmosphere of a normal school into that of a democratic and just community. The school moral atmosphere or moral climate refers to the values, meaning and norm systems that regulate informal social relationships within a school and to a degree that students share these values and norms with each other (16). For Brugman et al. (16), it is this school moral atmosphere that enables students to share experiences concerning their school and class and to perceive and interpret systematically and in accordance with the majority perspectives. Thus, ideally, the school as a community should have members who have common goals and a sense of shared purpose to which they all should, by definition, actively contribute, and feel committed. This shows that the school's moral atmosphere plays a critical role in determining how members of the school community view and relate to each other, to the school and its activities and how they (members) eventually behave $(17,18)$. The researchers that participated in the development of just community schools observed some striking changes in students' moral behavior; for example, fighting, stealing, cheating and truancy decreased, alcohol and drug abuse during school hours were eliminated. Other beneficial outcomes and consequences were an enhancement of educational aspiration, the improvement of black students' integration, and learning to participate in democratic meetings (19).

Also, research showed that school moral atmosphere could have long-term consequences for students' development. Power et al. (25) (1978) in their just community studies point to effects of moral atmosphere on students' prosocial behavior, career planning and moral judgment development. Further, Goodenow (1993) believed that there are positive relations between urban middle-school students' feelings of school belonging and their academic effort and motivation. Battistich, Solomon, Kim, Watson and Schaps (1995) reported relationships between elementary school students' sense of community and their academic motives and attitudes, personal and social attitudes, behavior and motives, and academic achievement. Hewstone, Jaspars and Lalljee (1982) found effects of school moral atmosphere on students' attribution style and their identity (cited in Beem (10)).

In this regard, Host et al. (19) and Brugman et al. (16) have established that the school's moral atmosphere affects students' behavior, academic performance, career planning, academic attitudes, life attitudes, motives, social and personal attitudes. Thus, it is important for the school's moral atmosphere to be explored since it directly contributes to pupils' socialization, academic development and school career in general (17).

Host et al. (19) in the Netherlands found that raising the level of moral atmosphere at a school resulted in significant reductions in thefts by pupils. Also, researchers found in the United Kingdom, there was a link between moral atmosphere and transgressions of moral norms. These studies found a link between moral atmosphere and behavior (17).

In addition to what was said, researchers found rela- 
tionships between school factors such as students' perception of school moral atmosphere and antisocial and prosocial behavior (20-23); students' moral reasoning competence and practical judgment at school $(24,25)$; aggressive and norm transgressive behavior in adolescents $(15,16,26$, 27); moral functioning (28); and social competence (10).

Overall, according to the research findings, it could be said that there is a positive relationship between culture and atmosphere of school and students' moral behavior and moral development. In fact, researchers showed that desirable institution climate or social context such as school has significant effects on real-life moral behavior and moral judgment. However, more studies are needed to explore the link between the school's moral atmosphere and students' moral behavior or moral development in different cultures and groups (17).

\section{Objectives}

The moral atmosphere of the school becomes a key factor influencing the moral development of young people. Consequently, this study focused on exploring the relationship between student perception of school moral atmosphere and their moral development in Iran's elementary schools.

According to the literature, we hypothesized that subscales of school moral atmosphere predict students' moral development.

\section{Patients and Methods}

The method of this research was descriptivecorrelative. The statistical population consisted of Shiraz elementary school students. The multi-stage cluster random sampling method was used to select 412 participants (grades four to six students) from different schools. They completed self-report questionnaires tapping the school moral atmosphere questionnaire and moral judgment test in the classroom during a 45-minute school lesson. All descriptive statistics, regression and confirmatory factor analyses, were performed with the SPSS 19 software. To analyze the data, relationships between variables were examined, using Pearson's product-moment correlations. Also simultaneous multiple regression was performed to investigate the prediction of students' moral competence through their perception of school moral atmosphere.

\subsection{Research Tool}

Two questionnaires including the school moral atmosphere questionnaire (SMAQ) and moral judgment test (MJT) were used in the current study.

\subsubsection{School Moral Atmosphere Questionnaire (SMAQ)}

The school moral atmosphere questionnaire (SMAQ, 29 ) is a multiple-choice instrument. This questionnaire is used to measure students' perception of school moral atmosphere. Actually, this instrument focuses on the individuals' perception of the moral atmosphere, and not on the moral atmosphere of the school as a whole, as constructed by the researcher. In this instrument, two real-life school dilemmas (one about helping an unpopular classmate and the other about stealing from a classmate) are presented. These dilemmas are used to measure the content of collective norms helping and stealing and the stage of collective moral reasoning on these norms.

In addition, it contains a five-point Likert (absolutely not true to absolutely true) questionnaire called questions about you and the school. In this questionnaire, students should answer questions from the perspective of the majority of their schoolmates. The questionnaire contains two scales that refer to connectedness with school and constraint. The first scale has three subscales: 1 , sense of community (11 items); 2, enthusiastic identification (6 items) and; 3, social relations (5 items). The second scale has two subscales: 1, negation of community (10 items) and; 2 , rejection school (5 items). Reliability and stability of this instrument were found to be satisfactory in earlier studies (29). The author of the measure, Daniel Brugman, granted the permission to use the questionnaire in the study. However, considering that the participants in the present study were elementary students, and according to Brugman, the Likert scale of this questionnaire, questions about you and the school-part 1, was used.

Also, in this study, to determine the reliability of the scale, Cronbach's alpha coefficient for all dimensions and general scale was calculated. Alpha coefficient for sense of community was 0.71 , for enthusiastic identification was 0.68 , for social relation was 0.66 , for negation of community was 0.69 , for rejection was 0.57 , and for general scale was 0.84 . Furthermore, for examining the validity of the scale, principle components analysis (factor analysis) and content validity were conducted. Factor analysis showed that the same factor solution was extracted from previous studies, confirming five factors of the scale. Also, content validity for use in Iran was approved by experts and scholars in this field.

\subsubsection{Moral Judgment Test (MJT)}

The MJT that was chosen for this study measures the ability of people to judge moral arguments pro and con a controversial moral problem on the basis of their own moral principles, that is, irrespective of their opinion on the particular problem (30). Lind believed that this test measures both moral attitude and moral competence. This 
test is a multiple-choice instrument and consists of two hypothetical situations, including workers' dilemma and mercy-killing dilemma. For rating, each dilemma is followed with a series of items and questions. Subjects should read each dilemma, evaluate the choice of the character in the story, and then rate six arguments in favor of the character's decision (pro arguments) and six arguments against the character's decision (contra arguments) on a scale of -4 (strongly reject) to +4 (strongly accept) (30). In this research, according to Lind, because the sample consisted of elementary students, the range of answers was reduced to -2 to +2 .

Lind believed that because using the indicators of validity and reliability such as Cronbach's alpha and criterion correlation are detrimental to the perception of cognitive-structural models of moral development, so, these indicators were not available for this test (30).

\section{Results}

Before analyzing the data, descriptive statistics for demographic and study variables was carried out and the results are shown in Tables 1 to 3.

Table 1. Demographic Characteristics of the Population $(n=412)$

\begin{tabular}{|c|c|}
\hline Variable & No. (\%) \\
\hline \multicolumn{2}{|l|}{ Gender } \\
\hline Girl & $222(53.88)$ \\
\hline Boy & $190(46.11)$ \\
\hline \multicolumn{2}{|l|}{ Age } \\
\hline $9-10$, (Fourth grade) & $120(29.13)$ \\
\hline $10-11$, (Fifth grade) & $151(36.65)$ \\
\hline $11-12$, (Sixth grade) & $141(34.22)$ \\
\hline
\end{tabular}

Table 2. Descriptive Statistics for PSDQ Scores $(n=412)$

\begin{tabular}{lc}
\hline PSDQ Scale & Mean \pm SD \\
\hline Sense of community & $41.53 \pm(7.59)$ \\
\hline Enthusiastic identification & $24.85 \pm(4.27)$ \\
\hline Social relations & $19.76 \pm(4.12)$ \\
\hline Negation of community $^{\mathrm{a}}$ & $30.48 \pm(7.72)$ \\
\hline Rejection school $^{\mathrm{a}}$ & $20.12 \pm(4.15)$ \\
\hline Total & $136.75 \pm(19.18)$ \\
\hline${ }^{\mathrm{a}}$ The marked scales are reversed. & \\
\hline
\end{tabular}

Table 3. Descriptive Statistics for Moral Judgment Test Scores $(n=412)$

\begin{tabular}{ll}
\hline MJT Scale & Mean \pm SD \\
\hline MJT Score & $16.58 \pm 12.24$ \\
\hline
\end{tabular}

Data analysis was then carried out first by calculating correlations between the measured variables. The Pearson correlations between all the measures are shown in Table 4.

As indicated, the results revealed that there were positive and significant correlations between students' perception of school moral atmosphere and moral competence.

As it can be observed, the following correlations between variables were significant: the correlation between all dimensions of moral atmosphere (expect of rejection school) with moral competence was significant.

Also, to investigate the prediction of student's moral judgment by their perception of school moral atmosphere simultaneous multiple regressions were performed. The results showed that among dimensions of moral atmosphere, sense of community and enthusiastic identification were significant positive predictors of moral competence. In addition, negation of community negatively predicts moral competence. The results are summarized in Table 5 .

\section{Discussion}

The aim of this study was to explore the relationship between perceived school moral atmosphere and moral competence in elementary students. Moral atmosphere at school is defined here as the perception of students of their schoolmates' and classmates' moral behavior, opinions and reasoning (10). Consistent with our hypothesis, we found that students' perception of moral atmosphere was a strong predictor of their moral judgment or moral competence. Our findings indicated the importance of the perception of moral atmosphere.

The mentioned study will investigate if differences in moral socialization are due to differences in perceived students' moral atmosphere. The just community studies express that the difference in perceived moral atmosphere between just community schools and normal schools results in long-term effects on students' educational career and moral behavior (19).

The just community approach helps to bridge the cultural gap between the student peer group and teachers. The goal is no longer to develop moral competence in individual students, but to develop the group as a moral com- 
Table 4. Correlations Between School Moral Atmosphere and Moral Competence

\begin{tabular}{|c|c|c|c|c|c|c|c|}
\hline Variable & $\mathbf{1}$ & 2 & 3 & 4 & 5 & 6 & 7 \\
\hline Sense of community & 1 & & & & & & \\
\hline Enthusiastic identification & $0.62^{\mathrm{a}}$ & 1 & & & & & \\
\hline Social relations & $0.69^{\mathrm{a}}$ & 0.60 & 1 & & & & \\
\hline Negation of community & $0.21^{\mathrm{a}}$ & 0.06 & $0.21^{\mathrm{a}}$ & 1 & & & \\
\hline Rejection school & $0.17^{\mathrm{a}}$ & $0.12^{\mathrm{b}}$ & $0.17^{\mathrm{a}}$ & $0.48^{\mathrm{a}}$ & 1 & & \\
\hline General moral atmosphere & $0.81^{\mathrm{a}}$ & $0.65^{\mathrm{a}}$ & $0.75^{\mathrm{a}}$ & $0.65^{\mathrm{a}}$ & $0.54^{\mathrm{a}}$ & 1 & \\
\hline Moral competence & $0.28^{\mathrm{a}}$ & $0.30^{\mathrm{a}}$ & $0.24^{\mathrm{a}}$ & $-0.21^{\mathrm{a}}$ & -0.07 & $0.13^{\mathrm{a}}$ & 1 \\
\hline
\end{tabular}

${ }^{\mathrm{a}} \mathrm{P}<0.001$

${ }^{\mathrm{b}} \mathrm{P}<0.01$.

Table 5. Multiple Regressions of School Moral Atmosphere on Moral Competence ${ }^{a}$

\begin{tabular}{|c|c|c|c|c|}
\hline \multirow[t]{2}{*}{ Variables } & \multicolumn{2}{|c|}{ Non-Standardized Coefficients } & \multirow{2}{*}{$\begin{array}{c}\text { Standardized Coefficients } \\
\beta\end{array}$} & \multirow[t]{2}{*}{ PValue $<$} \\
\hline & B & Standard Error & & \\
\hline Constant & 2.79 & 0.19 & & 0.000 \\
\hline Sense of community & 0.15 & 0.05 & 0.19 & 0.006 \\
\hline Enthusiastic identification & 0.13 & 0.04 & 0.17 & 0.007 \\
\hline Social relations & 0.45 & 0.04 & 0.07 & 0.292 \\
\hline Negation of community & -0.19 & 0.03 & -0.27 & 0.000 \\
\hline Rejection school & -0.00 & 0.03 & -0.00 & 0.901 \\
\hline
\end{tabular}

${ }^{\mathrm{a}} \mathrm{R}^{2}=0.18$.

munity found upon the norms of participation and collective responsibility. As they become involved in enforcing and making of disciplinary policies and rules, teachers and students experience a sense of shared responsibility for the school and feel they are members of a single community. This approach could help prevent and change counter-normative (particularly aggressive) behaviors and increase moral behaviors and moral judgment in students (26).

In other words, if students put their own prosocial choice and higher stage reasoning to the front and take each other's choice and reasoning seriously, they will perceive a higher stage moral atmosphere at school. When students perceive a higher stage school moral atmosphere, this could be less used as a self-serving bias to legitimize their own antisocial behavior (24). As a result, these students will show a higher moral competence in social situations.

From the results of these studies, we may conclude that in order to establish moral competence or judgment in school populations it would be much more gratifying to stimulate the moral atmosphere at school. As mentioned above, research on just community schools with volunteer students suggests that an improvement of the moral atmosphere results in long-term effects on prosocial and moral behavior, including students' moral competence (24). Therefore, for any program, which aims to raise students' moral judgment, improvement of perceived moral atmosphere needs to be included as the first goal (16). Possibly such report will create some pressure and enthusiasm in teachers about improving moral atmosphere. To achieve this goal they may try interventions that are in accordance with their own educational philosophy, and or which may reflect the just community approach (24).

One limitation of this study was that only self-report measures have been used. Large-scale research like the present study depends heavily on the use of questionnaires. Also, this study deals with students of elementary schools and the findings that were obtained cannot be extrapolated to other schools' populations.

Despite the limitations, the present results provide some considerable support for the importance of school atmosphere in the domain of moral development in elementary students. More research would be beneficial in 
further establishing the validity of this study, especially if conducted with other grades such as secondary students. Moreover, longitudinal research is needed to confirm the hypothesized direction of assumed relationships in the current study and to determine the impact of perception of school moral atmosphere on students' moral competence.

\section{Acknowledgments}

The authors wish to take this opportunity to acknowledge the schools and teachers who sincerely helped us with the data gathering.

\section{Footnote}

Authors' Contribution: Study conceptand design, Naeimeh Kohoulat; acquisition of data, Naeimeh Kohoulat; drafting of the manuscript, Naeimeh Kohoulat; critical revision of the manuscript, Parvin Kadivar, Gholamreza Sarami and Fariba Khoshbakht; statistical analysis, Naeimeh Kohoulat; technical support, Naeimeh Kohoulat; study supervision, Parvin Kadivar.

\section{References}

1. Carpendale JIM, Hammond SI, Atwood S. A relational developmental systems approach to moral development. 2013 ;45:125-53. doi: 10.1016/b978-0-12-397946-9.00006-3.

2. Wachob RA. Fostering moral development in preschoolers: the RAD (read, act and discuss) technique. 1998

3. Sabin B. A faith-based program evaluation: Moral development of seminary students at the Louisiana State Penitentiary. University of Central Florida Orlando, Florida; 2006.

4. Edwards CP, Carlo G. Introduction: Moral development study in the 21st century. 2005

5. Buchsbaum HK, Emde RN. Play narratives in 36-month-old children. Early moral development and family relationships. Psychoanal Study Child. 1990;45:129-55. [PubMed: 2251303].

6. Lotfabadi H. Criticism on moral development theories of Piaget, Kohlberg, and Bandura and providing a new model for research in Iranian students' moral development. Quarter J Edu Innovat. 2008;24:31-46.

7. Lane JD, Wellman HM, Olson SL, LaBounty J, Kerr DC. Theory of mind and emotion understanding predict moral development in early childhood. Br J Dev Psychol. 2010;28(Pt 4):871-89. [PubMed: 21121472].

8. Ma HK. The Moral Development of the Child: An Integrated Model. Frontiers in Public Health. 2013;1 doi: 10.3389/fpubh.2013.00057.

9. Van Vugt E, Gibbs J, Stams GJ, Bijleveld C, Hendriks J, van der Laan P. Moral development and recidivism: a meta-analysis. Int J Offender Ther Comp Criminol. 2011;55(8):1234-50. doi:10.1177/0306624X11396441. [PubMed: 22114168]

10. Beem AL, Brugman D, Host K, Tavecchio LWC. Students' perception of school moral atmosphere: From moral culture to social competence. A generalizability study. Eur J Soc Psychol. 2004;1(2):171-92. doi: $10.1080 / 17405620444000076$

11. Ma HK. Moral Competence as a Positive Youth Development Construct: A Conceptual Review. Sci World J. 2012;2012:1-8. doi: $10.1100 / 2012 / 590163$.
12. Ma HK. Moral competence as a positive youth development construct: conceptual bases and implications for curriculum development. Int J Adolesc Med Health. 2006;18(3):371-8. [PubMed:17068918].

13. Westman AS, Lewandowski LM. How empathy, egocentrism, Kohlberg's moral development, and Erikson's psychosocial development are related to attitudes toward war. Psychol Rep. 1991;69(3 Pt 2):1123-7. doi: 10.2466/pro.1991.69.3f.1123. [PubMed: 1792278].

14. Jensen LA. Moral Development. Chicago: The University of Chicago Press; .

15. Batanova M, Loukas A. Unique and interactive effects of empathy, family, and school factors on early adolescents' aggression. J Youth Adolesc. 2014;43(11):1890-902. doi: 10.1007/s10964-013-0051-1. [PubMed: 24198084].

16. Brugman D, Podolskij A, Heymans P, Boom J, Karabanova O, Idobaeva O. Perception of moral atmosphere in school and norm transgressive behaviour in adolescents: An intervention study. Int J Behav Dev. 2003;27(4):289-300. doi:10.1080/01650250244000272.

17. Mushoriwa TD. Pupils' Perceptions of the Moral Atmosphere in Some Secondary Schools in Harare, Zimbabwe. East Mediterr Health J. 2014 doi: 10.5901/mjss.2014.v5n20p1596.

18. Karabanova OA, Sadovnikova TY. The comparative research of adolescent's school moral atmosphere perception in modern russia. Procedia Soc Behav Sci. 2014;146:395-400. doi:10.1016/j.sbspro.2014.08.143.

19. Host K, Brugman D, Tavecchio LWC, Beem L. Students' Perception of the Moral Atmosphere in Secondary School and the Relationship Between Moral Competence and Moral Atmosphere. J MORAL EDUC 1998;27(1):47-70. doi:10.1080/0305724980270104.

20. De Wolff MS, Brugman D. Moral atmosphere and moral behavior: A study into the role of adolescents' perception of moral atmosphere for antisocial behavior. The development and structure of conscience. 2010:135-50.

21. Barr JJ, Higgins DA. How adolescent empathy and prosocial behavior change in the context of school culture: a two-year longitudinal study. Adolescence. 2009;44(176):751-72. [PubMed: 20432599].

22. Barr JJ, Higgins DA. Adolescent empathy and prosocial behavior in the multidimensional context of school culture. $J$ Genet Psychol. 2007;168(3):231-50. doi: 10.3200/GNTP.168.3.231-250. [PubMed 18200888].

23. Wissink IB, Dekovic M, Stams GJ, Asscher JJ, Rutten E, Zijlstra BJ. Moral orientation and relationships in school and adolescent pro- and antisocial behaviors: a multilevel study. J Sch Nurs. 2014;30(3):216-25. doi: 10.1177/1059840513497402. [PubMed: 23873393].

24. Brugman D, Tavecchio LWC, Van Os BJ, Host K. Students' perception of moral atmosphere in secondary schools: Their moral reasoning competence, and their practical judgement in school. University of Bath Press Bath; 1999.

25. Power C, Reimer J. Moral atmosphere: An educational bridge between moral judgment and action. New Directions for Child and Adolescent Development. 1978;1978(2):105-16. doi:10.1002/cd.23219780209.

26. Foa C, Brugman D, Mancini T. School moral atmosphere and normative orientation to explain aggressive and transgressive behaviours at secondary school. J MORAL EDUC. 2012;41(1):1-22. doi 10.1080/03057240.2011.652520.

27. Mancini T, Fruggeri L, Panari C. An extention of the school moral at mosphere construct, and its association with aggressive behaviours in secondary school. EUR J PSYCHOL EDUC. 2006;21(2):209-28. doi $10.1007 /$ bfo3173577.

28. Steinfeldt JA, Rutkowski LA, Vaughan EL, Steinfeldt MC. Masculinity, moral atmosphere, and moral functioning of high school football players. J Sport Exerc Psychol. 2011;33(2):215-34. [PubMed: 21558581].

29. Koops W, Brugman D, Ferguson TJ, Sanders AF. The development and structure of conscience. Psychology Press; 2009.

30. Stephens DG. A correlational study on parental attachment and moral judgment competence of millennial generation college students. 2009 